\title{
Psychosocial factors related to adolescent smoking: a critical review of the literature
}

\author{
Suzanne L Tyas, Linda L Pederson
}

\begin{abstract}
Objective-To extend the analysis of psychosocial risk factors for smoking presented in the United States surgeon general's 1994 report on smoking and health, and to propose a theoretical frame of reference for understanding the development of smoking.

Data sources-General Science Index, Medline, PsycLIT, Sociofile, Sociological Abstracts, and Smoking and Health. Holdings of the Addiction Research Foundation of Ontario Library as well as the authors' personal files.

Study selection-Reviewed literature focused on studies that examined the association of sociodemographic, environmental, behavioural, and personal variables with smoking.

Data synthesis-Adolescent smoking was associated with age, ethnicity, family structure, parental socioeconomic status, personal income, parental smoking, parental attitudes, sibling smoking, peer smoking, peer attitudes and norms, family environment, attachment to family and friends, school factors, risk behaviours, lifestyle, stress, depression/distress, selfesteem, attitudes, and health concerns. It is unclear whether adolescent smoking is related to other psychosocial variables. Conclusions-Attempts should be made to use common definitions of outcome and predictor variables. Analyses should include multivariate and bivariate models, with some attempt in the multivariate models to test specific hypotheses. Future research should be theory driven and consider the range of possible factors, such as social, personal, economic, environmental, biological, and physiological influences, that may influence smoking behaviour. The apparent inconsistencies in relationships between parental socioeconomic status and adolescent disposable income need to be resolved as does the underlying constructs for which socioeconomic status is a proxy.

(Tobacco Control 1998;7:409-420)
\end{abstract}

Keywords: adolescence, smoking initiation, psychosocial factors

\section{Introduction}

In recent years, increasing efforts have been made to reduce the prevalence of tobacco use and the exposure to environmental tobacco smoke in both the United States and Canada. These efforts have been somewhat successful: the prevalence of smoking in the general population has declined by over $15 \%$ in the past 25 years. ${ }^{1-4}$ The reduction seen in adults, however, has not been noted in adolescents, ${ }^{5-8}$ particularly young females. ${ }^{9}{ }^{10}$ In addition, the stable rates of the recent past have changed in the past two years and now indicate a rise in smoking among young people. ${ }^{11}$

The argument for smoking prevention among adolescents is based on the observation that, if smoking does not start during adolescence, it is unlikely ever to occur ${ }^{8}$ and on data indicating that the probability of cessation among adults is inversely related to age at initiation. ${ }^{12}{ }^{13}$ Even infrequent experimental smoking in adolescence significantly increases the risk of adult smoking. ${ }^{14}$ Once smoking has begun, cessation is difficult and smoking is likely to be a long-term addiction. For example, it has been estimated that the median cessation age, for those born from 1975 through 1979 who begin smoking in adolescence, is 33 years for men and 37 years for women. ${ }^{15}$ Based on a median initiation age of 16 to 17 years, the predicted duration of smoking is 16 and 20 years for $50 \%$ of the males and females respectively. Prevention of the onset of adolescent smoking is thus an essential component of efforts to reduce the overall prevalence of smoking and its attendant morbidity and mortality.

Although there are educational programmes available with demonstrated effectiveness in reducing the prevalence of adolescent smoking over the short term, the longer term evaluations are not as encouraging. ${ }^{816-21}$ The differences in smoking levels between treated and control groups appear to dissipate over time, and disappear completely after six years. Further evaluations of these educational efforts are warranted, with consideration given to methodological problems inherent in such studies (such as potential bias resulting from losses to follow up, and possible effects of interventions other than the one being evaluated). There is, however, also a need to continue to examine research on the aetiology of smoking in young people. Research and theory must be directed toward understanding why some individuals smoke and others do not. 


\section{Theoretical considerations}

Some of the research in adolescent smoking is grounded in theory, whereas other studies have a more empirical orientation. There are four theoretical bases that have been used to explain the initiation to and the acquisition of smoking. They include the rational approach as presented by Ajzen and Fishbein, ${ }^{22}$ social learning theory as found in the work of Bandura, ${ }^{23}$ emphasis on social norms and attitudes as reflected by the research of Jessor and Jessor, ${ }^{24}$ and the developmentally oriented affective approach of Rosenberg. ${ }^{25}$ All of these explanations have found support in at least some studies; there is thus no one clearly superior model that can be used to explain adolescent smoking. A complication for programme design is that the relevance of different types of variables, and possibly theoretical orientations, appears to vary depending on the stage of acquisition (see review by Flay $^{26}$ ).

\section{Objective}

Given the above considerations concerning prevalence and incidence of smoking, it appears timely that a review of the literature be conducted to synthesise and integrate the vast amount of information available on variables related to smoking by adolescents. The outcome of this review is to provide the basis for specific recommendations concerning future research, theory, and programmes aimed at reducing adolescent smoking. The specific approach that is taken in this review is to extend the analysis of psychosocial risk factors for smoking presented in the United States surgeon general's 1994 report, ${ }^{8}$ and to propose a theoretical frame of reference for understanding the development of smoking. To meet these objectives, studies that examined the association of sociodemographic, environmental, behavioural, and personal variables with adolescent smoking were reviewed, as well as theory-based research aimed at understanding the mechanisms underlying initiation to smoking.

\section{Methods}

DATA SOURCES AND STUDY SELECTION

The following literature databases were searched: General Science Index, Medline, PsycLIT, Sociofile, Sociological Abstracts, and Smoking and Health. Holdings of the Addiction Research Foundation of Ontario Library as well as references in the authors' personal files were also examined. Studies were selected if they related directly to smoking; relevant articles which dealt with the acquisition of other substance abusing behaviours were reviewed but not summarised in the tables. Only studies published in English or French were included. The search was confined to studies published from 1984 to 1996.

\section{METHODOLOGICAL CONSIDERATIONS}

The methods used to collect and analyse data must be examined to reconcile at least some of the inconsistencies observed in reported results. These methodological issues include differences in the measures used and the definitions of predictors and smoking behaviours, the study design (that is, cross-sectional or longitudinal), sample sizes, losses to follow up and drop outs, data collection methods, target populations and response rates, age groups included, and the use of biochemical validation of reported behaviour. Some studies reported initiation to smoking and factors related to it, whereas others focused on current daily and occasional smoking, and relevant predictor variables. Furthermore, some studies assessed statistical relationships using bivariate analyses; in other reports, the same relationships were examined with potential confounders controlled. As a result, the inconsistencies in reported findings were not unexpected.

DATA SELECTION AND FRAMEWORK

There were numerous frameworks that could have been adopted for this review-for example, refs ${ }^{26-29}$. The one chosen was based on the surgeon general's report ${ }^{8}$; the only modification was that articles examining prior smoking as a risk factor for subsequent smoking were grouped with other predictor variables of substance use in behavioural factors, rather than in a separate section. The categories were mutually exclusive and exhaustive (sociodemographic, environmental, behavioural, and personal factors). The variables to be discussed were listed at the beginning of each section. Many of the studies were cited under more than one category of risk factors because they included a range of variables.

DATA EXTRACTION AND TABULAR PRESENTATION The research literature was summarised in four detailed tables (available from LLB), one for each of the sections on sociodemographic, environmental, behavioural, and personal factors. Each table included information on the study's author(s); date of publication; place in which the research was conducted; age(s) of the subjects; duration of follow up, if any; sample size, by group if relevant; outcome and predictor variables; results; notes concerning the analysis, any unusual aspects of the methods, and statements concerning special findings; and other tables under which the study was summarised. Both statistically significant and non-significant results were indicated.

The table in this report provides an overall summary of the evidence for an association between the major variables discussed and adolescent smoking. The major trends in the studies were noted and overall conclusions drawn, with indications of areas in which there were contradictory or inconsistent findings. The summary of whether a particular variable was associated, not associated or the presence of an association was undecided was based on standard statistical levels of significance $(p<0.05)$. The overall conclusions did not depend entirely on the number of studies, but considered study design and analytical methods; the results of longitudinal studies and analyses adjusted for confounders were given more influence. An association was judged undecided if inconsistently observed or 
Summary of the association of psychosocial factors with adolescent smoking

\begin{tabular}{l}
\hline Factors \\
Sociodemographic \\
Age \\
Gender \\
Ethnicity/race \\
Acculturation \\
Family structure \\
Parental socioeconomic status \\
Personal income \\
Urban/rural residence \\
Environmental \\
Parental smoking \\
Parental attitudes \\
Sibling smoking \\
Peer smoking \\
Peer attitudes and norms \\
Family environment \\
Attachment to family and friends \\
Availability of tobacco \\
Behavioural \\
School factors \\
Risk behaviour \\
Lifestyle
\end{tabular}

if such an association had not yet been sufficiently investigated to warrant a conclusion. Both authors independently reviewed the literature and came to the same conclusions regarding the current evidence for an association between each factor and adolescent smoking.

\section{DATA SYNTHESIS}

Sociodemographic factors

The factors summarised included age; gender; ethnicity and acculturation; living arrangements, family size and structure; parental socioeconomic status (SES); spending money and employment status; and rural/urban residence. In some studies, it was difficult to separate these factors because there are collinear relationships between such variables as SES, family size, and educational level of parents. There was also considerable overlap between the studies in this section and others, because almost all of the studies in this review examined some sociodemographic variables.

Initiation and prevalence of smoking among adolescents typically rise with increasing age and grade-for example, refs ${ }^{30-33}$. Adolescents who began smoking at a younger age were more likely to become regular smokers ${ }^{34}$ and less likely to quit smoking. ${ }^{13}$

Although historically the prevalence of smoking was higher among men than women, ${ }^{8}$ data collected for the past 10 years have revealed that the rates of current smoking and initiation to smoking were approximately equal for the two groups, at least in North America. For adolescents, however, reported smoking rates among girls were higher than for boys in some studies from the 1980 s, with conflicting accounts in other reports of no gender differences or higher rates among boys. The results of the studies initially appear inconsistent, but further examination reveals a geographical/cultural pattern of gender differences. Reports of equal or higher levels of smoking by females were primarily found in studies with subjects from countries with a Western cultural orientation: England, New Zealand and the United States, ${ }^{31}{ }^{35-40}$ rather than an "Eastern" one with higher smoking levels among males: China, Japan, and Sri Lanka. ${ }^{41-45}$ Also consistent with this pattern of East/West differences was a report from the United States of a significantly higher risk of current smoking among Vietnamese boys, whereas the risk was lower among white and Hispanic boys than among girls of these same ethnic/racial groups. ${ }^{46}$ These patterns reflect the gender differences found among adults in these countries. ${ }^{47-49}$

There were a few exceptions to this pattern in the articles summarised. In Canada, a significantly higher prevalence of smoking in males $(20.5 \%)$ than females $(18.4 \%)$ was reported, ${ }^{50}$ whereas the opposite might be expected. Possible explanations for this inconsistent result are the study's inclusion of older subjects (half of the subjects were aged 18 to 24 years), who would be more likely to show the pattern of slightly higher rates of smoking seen in adult Canadian men, ${ }^{2}$ or the small gender difference (odds ratio $=1.13$ for males) that only reached statistical significance because of the large sample size $(n=8018)$. One other article reported discrepant results. A study of Icelandic adolescents found higher levels of smoking for adolescent girls, ${ }^{51}$ as might be expected, but a study in another Nordic country, Finland, found higher smoking rates for boys. ${ }^{52}$

The reasons for the recent increase in smoking rates for girls in the West are diverse and probably include such factors as focused advertising and concerns about weight control. Reasons for smoking are likely to be different for males and females and have been discussed in Pederson, ${ }^{53}$ Pederson and Lefcoe, ${ }^{54}$ Koval and Pederson, ${ }^{55}$ and in the section below, on personal factors. Despite the potential differences in mechanisms, however, smoking rates among boys and girls were often similar, with many studies reporting non-significant gender differences.

The rates of smoking for North American aboriginal peoples are consistently the highest of any ethnic group studied-for example, refs $^{56}{ }^{57}$. It is well documented, however, that blacks show significantly lower levels of initiation and current smoking than whites or Hispanics-for example, refs $^{5658}$. The reasons for this difference are not clear, particularly given that many of the variables associated with smoking, such as low SES, poverty, dysfunctional families, and low educational aspirations, tend to cluster in some "black" geographical areas. Among blacks who do smoke, the mechanisms may be different from those for whites; smoking may serve more of a social function for white adolescents because they are more strongly influenced by peer smoking. ${ }^{60}$ Smoking levels appear to be relatively high among Hispanic youth; they have variously been reported as higher than for white adolescents (for example, ref $^{58}$ ), lower 
(for example, $\operatorname{refs}^{3456-62}$ ), and higher and lower, depending on the level of acculturation. ${ }^{63}$

It might be expected that the degree to which individuals from various ethnic backgrounds identify with, or have been assimilated into, mainstream society would be related to the adoption of certain behaviours, including smoking. In the United States, Landrine and colleagues ${ }^{63}$ found that acculturated Latinos showed smoking rates similar to those of whites; less acculturated Latinos showed significantly lower smoking rates similar to those of blacks and Asians. Vega et al ${ }^{62}$ did not find an effect of acculturation among Hispanic groups and Wiecha ${ }^{46}$ reported an inverse association of acculturation and smoking for Vietnamese adolescents. The influence of acculturation is thus not clear; some possible explanations for the discrepancies may be differences in the smoking rates across subjects' countries of origin, analytic differences (acculturation was assessed using univariate analyses in Wiecha ${ }^{46}$ ), and age differences (in the study by Vega et $a l^{62}$ subjects were several years younger than those in either of the other two studies and had relatively low levels of smoking).

Variables related to family structure have been examined in many studies. Overwhelmingly, the evidence leads to the conclusion that intact, two-parent families are protective against smoking-for example, refs ${ }^{52}{ }^{64-66}$. This association has persisted over the past decade and across countries.

The effect of household size on risk of smoking is unclear: studies have noted larger families to be associated with lower ${ }^{5067}$ or higher levels ${ }^{52}$ of smoking, or have reported no significant relationship. ${ }^{40}$ The inconsistent results might reflect differences in whether analyses controlled for associated variables such as parental income, parental education, and smoking by siblings and other household members. In large households, there is a greater chance that at least one member will smoke and that there will be a higher number of smokers; if no household member smokes, then there is no increase in risk associated with household size or, in fact, the additional non-smoking models may decrease the risk of adolescent smoking.

Higher levels of parental socioeconomic variables, such as education and social class, have often been found to be inversely related to smoking status in adolescents-for example, refs $^{4045526869}$. The effect of SES may explain some of the inconsistent results for maternal and paternal education. Several studies that have reported non-significant effects of parental education on adolescent smoking have examined maternal education only ${ }^{30} 7^{70}$ or have found paternal but not maternal education to be significant. ${ }^{44}$ Traditionally, however, paternal education has been a stronger determinant of household SES than maternal education, whereas maternal educational level has been associated with the health behaviours in a household.
The personal income of adolescents has been associated with adolescent smoking: young people with more spending money showed higher levels of smoking ${ }^{38} 40517172$ presumably because money is needed for the purchase of cigarettes. Adequate income may supersede other protective factors; Blackford, Bailey, and Coutu-Wakulczyk ${ }^{73}$ found that subjects who were working and had their own personal income showed higher cigarette use even though they came from two-parent families.

Relatively few studies included measures of rural/urban status and the results of these studies were inconsistent. A higher prevalence of smoking was associated with residence in a rural, tobacco-producing area in the United States $^{74}$ and urban residence in Sri Lanka. ${ }^{43}$ Isohanni and colleagues ${ }^{52}$ noted increased smoking by young people living in urban areas, but decreased smoking by those living in an industrialised province. Two other reports found no significant relationship. ${ }^{4051}$

\section{Environmental factors}

Factors in the environment that potentially influence initiation and maintenance of smoking by adolescents have been the focus of many investigations since early studies demonstrated the importance of peer and parental smoking as risk factors. ${ }^{75}$ The broad categories that have been studied are: smoking among parents, siblings and peers; attitudes and norms about smoking (including parental reactions to smoking by their children); family environment; and attachment to family and friends. Availability and ease of acquiring cigarettes are also environmental factors that can have an impact on smoking among adolescents. Interpretation of these studies was complicated by inconsistencies in the outcome variable (smoking status, intentions, initiation, and attitudes); the different combinations of predictor variables; the range of methods and populations; and the variety of analytical approaches that have been used.

The impact of parental smoking has been studied in a wide range of contexts in a large number of studies with a variety of outcomes. Approximately twice as many of the reviewed studies have found a significantly increased risk of adolescent smoking with parental smoking-for example, refs ${ }^{52} 7076$, than have noted a non-significant association. ${ }^{43} 7879$ Studies examining the effect of paternal and maternal smoking separately have reported both to be significant, ${ }^{36}$ non-significant, ${ }^{31}{ }^{80}$ or each one significant while the other was not. ${ }^{81}{ }^{82}$ Some of the inconsistencies may reflect gender-specific differences: parental smoking may be more important for girls than boys because several studies reported a significant effect only for girls $^{38} 698384$ whereas none found the reverse. It is unclear whether parental smoking has a stronger influence when it occurs in the samegender parent: reports have both supported and opposed this hypothesis. ${ }^{6785} \mathrm{~A}$ doseresponse effect may also be present, with a stronger influence if both parents smoke. ${ }^{41} 71$ Finally, some reports noted that the significance of parental smoking depended on 
the outcome studied. It was significant only for intention to smoke and not for current smoking in one study. ${ }^{86}$ Another study found paternal smoking significant for current smoking but not for experimental smoking, whereas maternal smoking was significant for both. ${ }^{32}$

Parental attitudes toward smoking and, in particular, toward their own children's smoking have been shown to be related to adolescent smoking. For example, Newman and Ward ${ }^{76}$ found that parental indifference to their child's smoking increased the likelihood of smoking in American 13-14 year olds. Similar results were found by Dusenbury and colleagues $^{32}$ for current and experimental smoking in the United States and by Wang and colleagues $^{30}$ for weekly or daily smoking among adolescents in China. Botvin et $a l^{31}$ found parental attitudes to be related to smoking in Black students in bivariate but not multivariate analyses, as did McNeill and colleagues ${ }^{35}$ for English adolescents starting to smoke. Adult smoking norms were not related to either smoking behaviour or intentions in grade 7 inner-city youth $\left(12-13\right.$ year olds). ${ }^{87}$

The weight of the summarised studies supports the influence of sibling smoking on adolescent smoking-for example, refs $^{3741458688}$. Some of the studies reporting non-significant results did find a significant effect of sibling smoking before controlling for other variables in multivariate analyses. ${ }^{36} 89$ In some studies, the influence of smoking by siblings was stronger than that of smoking by parents-for example, refs ${ }^{31490}$. Sibling but not parental smoking was also associated with less negative attitudes towards smoking. ${ }^{91}$ Given the influence of parental and sibling smoking, it is not surprising that some adolescents attributed their own initiation to smoking to the fact that one or more of their family members smoked. ${ }^{36} 7392$

Aspects of the family environment which have been examined with regard to adolescent smoking include parental supervision, attachment, support, and parenting style. The amount of time in self care, ${ }^{93}$ lack of knowledge about their children's friends ${ }^{78}$ and inadequate monitoring ${ }^{77}$ were associated with increased smoking, although other studies on parental supervision did not observe a significant relationship. ${ }^{79} 9596$

The most important component of parental attachment may be attachment to the mother: it has been related to smoking in studies where attachment to the father was not significant. ${ }^{78} 97$ A poor relationship between mother and child was associated with a higher prevalence of smoking for boys and girls; a poor father/child relationship significantly influenced smoking only for girls. ${ }^{38}$

Parental attachment and support may interact with parental smoking to influence smoking among adolescents. Parental and other adult support was protective against adolescent smoking mainly at low levels of parental smoking. ${ }^{98}$ Adolescents modelled their parents' smoking status more closely as attachment to their parents increased. ${ }^{99}$
An authoritative, positive parenting style has been associated with lower levels of adolescent smoking. ${ }^{1001}$ Some aspects of child rearing, however, may have differential effects for males and females. Low parental concern increased the risk of boys taking up regular smoking ${ }^{84}$ whereas poor communication with parents and restrictions on going out raised the prevalence of smoking in girls. ${ }^{38}$ A permissive, distracted family environment was also related to illicit drug use in girls. ${ }^{102}$

Findings with regard to peer smoking were more consistent than those for parental smoking. "Peers" have been variously defined as classmates, friends, best friends, opposite or same sex friends, and boyfriends or girlfriends. The influence of best friends has been noted to be greater than that of other good friends which, in turn, was greater than that of peers of the same age. ${ }^{103}$ Regardless of the definition used, however, peer smoking was consistently found to be related to adolescent smoking initiation, maintenance and intentions-for example, refs ${ }^{31} 77104105$. Some of the inconsistency in the reported influence of parental smoking on adolescent smoking may reflect whether peer smoking was also examined, because the effect of parental smoking may become non-significant after controlling for peer smoking - for example, ref ${ }^{89}$. It is less the existence of a causal relationship between peer and individual smoking than the direction of that association that has been a matter of debate. ${ }^{106} 107$ It is unclear whether peer influence leads to smoking or whether individuals who smoke tend to seek out other smokers.

Peer influence may be modified by group membership: smoking by best friends was found to be related to adolescent smoking for group outsiders but not for group members. ${ }^{108}$ This result was supported by the observation of Ennett and Bauman ${ }^{106}$ that social isolates were more likely to become smokers.

Normative values appear to play a role; different measures of smoking were related to "pressure to smoke" and "pressure not to smoke" 31109110 but not to actual prevalence of smoking. ${ }^{32} 36111$ In addition, adolescent smokers tended to overestimate the prevalence of smoking among peers. ${ }^{3287109110}$ The perceived prevalence of adult smoking is less clear; one study found that adolescent smokers overestimated smoking among adults ${ }^{110}$ whereas other studies did not. ${ }^{32} 87$ Perceived smoking by friends, however, was reported to be a stronger predictor of cigarette use than friends' actual use. ${ }^{112}$ Some factors may be differentially important at different ages. For example, Santi et $a l^{90}$ found that "best friend tried smoking" was related to smoking initiation during elementary school and "most of five closest friends tried smoking" was related to smoking initiation during high school.

The extent to which the individual is bonded or attached to peers is perhaps the underlying mechanism for the influence that peers exert on adolescent behaviour. Various constructs used to describe this phenomenon include 
social support, need for affiliation, social bonding, and attachment. Peer attachment has been reported to raise the risk of adolescent smoking. ${ }^{78}$ Peer support had no influence when friends were non-smokers, but increased smoking when peers smoked and there was little parental or other adult support. ${ }^{98}$ Peer indifference or approval of smoking - for example, refs $^{43} 103$ and drug use $e^{94}$ has been associated with increased adolescent smoking: Urberg and colleagues ${ }^{109}$ observed that smokers do not believe that peers encourage smoking, but that they do not discourage it.

The observation that peer variables appear important across ages and countries probably indicates something about the way adolescents learn to function in society. The consistency and magnitude of the relationships lead to conclusions about the power of social connections for maturation and for the adoption of behaviours as well as attitudes and beliefs.

The final variable to be discussed in this section is the accessibility of tobacco. Tobacco is generally available to adolescents. Despite legislation that prohibits sales to minors, they are able to acquire cigarettes and other tobacco products through direct purchase themselves, ${ }^{113}$ through older friends and family members, or by stealing from parents and other adults who smoke. Although accessibility is important, it has been shown to be less so than other reasons cited for smoking. ${ }^{39}$

\section{Behavioural factors}

There were three major categories of behavioural variables. First were those factors related to school, primarily academic performance and aspirations. A second category contained risk-taking or deviant factors such as violence and gang membership. A final related grouping included lifestyle factors such as diet, exercise, sleep, and dental care. Behaviours related to sexual activity, seatbelt use, and alcohol and other drug use are indicators of lifestyle, but also can be described as risk-taking.

Smoking status has been found to be consistently related to school performancefor example, refs ${ }^{81-114}$, and has also been associated with educational aspirations, ${ }^{3041}$ and commitment to school. ${ }^{105}$ Those students who do well in school, have high academic aspirations and are committed to school are less likely to smoke than those who do not possess these characteristics. The protective effect of academic performance, aspirations, and commitment on adolescent smoking may reflect beliefs necessary for academic success. A longitudinal study of American 12-14 year olds found that belief in conventional rules was associated with lower levels of smoking. ${ }^{99}$

Risk taking and deviance encompass a pattern of problem-prone behaviours that frequently tend to coincide. For example, measures of deviance and risk-taking were related to trying to smoke, ${ }^{104}$ current smoking, ${ }^{115}$ and to associating with smoking friends. ${ }^{95}$ As well, certain risky behaviours such as having a history of trouble with the police ${ }^{94}$ and, for some ethnic groups, carrying a weapon ${ }^{46}$ were also associated with smoking. Although not all studies have shown this relationship - for example, ref ${ }^{33}$, overall results tended to support this pattern.

Lifestyle behaviours tend to occur together in adults, so that individuals who adopt a healthy lifestyle with regard to one aspect of their lives tend to do so in others as well. ${ }^{116}$ This pattern also appears to occur in adolescents. For example, problem behaviours such as smoking and other drug use, sexual activity, riding with a drinking driver, carrying a weapon, and physical fighting have been associated with lower levels of healthenhancing behaviours such as seatbelt use, positive eating behaviour, and adequate sleep. ${ }^{117}$ Alcohol and other drug use increased the risk of smoking among adolescents-for example, $\mathrm{refs}^{3858118}$ whereas participation in sports or other physical exercise consistently protected against smoking-for example, refs $^{34} 52119$.

Not following a healthy lifestyle can be considered a form of risk taking if the individual has knowledge of its health implications. Although this knowledge was not assessed in some of the studies reviewed, it is unlikely that young people are unaware of the health risks of unprotected sexual activity or the use of tobacco, alcohol, and other drugs. Hence, adoption of behaviours such as these can be considered to be risk taking in most adolescents. Research results supported the conclusion that these unhealthy practices were related to smoking initiation and maintenance in a wide range of settings-for example, refs $^{35} 5094$.

\section{Personal factors}

Research on psychosocial correlates of smoking and other drug use, specifically investigations of personality characteristics, motivational factors such as stress, and personal resources such as coping, has arisen from attempts to delineate the mechanisms explaining initiation to smoking among some population subgroups defined by their sociodemographic characteristics. ${ }^{120-132}$ These studies are summarised in this section. Research on smoking knowledge and attitudes, sex roles, socialisation, and religiosity has also been included in this section because of their interrelationships and their functions as proximal determinants of smoking.

In addition to the methodological and analytic issues raised earlier, the problems in interpretation of the factors in this section were compounded by the use of concepts that were given the same name but measured different constructs (such as stress: acute or chronic) or that were given different names but measured similar constructs (for example, competence and locus of control). In addition, the different combinations of variables included make it difficult to draw definitive conclusions about any single variable. Some overall statements, however, can be made about the influence of personal variables on adolescent smoking.

Stress and associated distress or depression are important factors in the initiation to smok- 
ing. It has long been recognised that life change or life stress may have a substantial negative impact on emotional wellbeing. It is the unsuccessful adjustment to this life change that is postulated to lead to psychological distress. Indeed, in adult and adolescent samples, stress has been shown to be positively correlated with levels of psychological distress. ${ }^{133}{ }^{134}$ It has been repeatedly demonstrated that stress, measured in a variety of ways, is associated with initiation to smoking and with maintenance of the behaviour-for example, refs ${ }^{135-137}$. For those studies that do not include a direct measure of stress, the impact can be implied through associations with its outcomedepression/distress ${ }^{64138139}$.

The use of smoking for dealing with stress is not unexpected as nicotine may have direct pharmacological effects that moderate stress. ${ }^{140-144}$ In fact, smoking has been cited as a means of dealing with stress among young smokers ${ }^{145}$ as well as among adults. Although there is some evidence that drugs in general are used for coping, ${ }^{146-148}$ Wills and Shiffman, ${ }^{133}$ in their review of the literature, noted that smoking was consistently reported to be a coping mechanism. The relationship of smoking status and the availability of other coping strategies for dealing with stress has been investigated with significant ${ }^{38}$ and non-significant results. ${ }^{94}$ Pederson and colleagues ${ }^{19}$ reported that, although a total coping score was not associated with ever/never-smoking, problem solving was higher in never-smokers, and drug use and ventilation of feelings were more likely to be used as coping strategies in ever-smokers.

Other factors that have been consistently associated with smoking are self-esteem, whether overall or with regard to specific contexts such as home or school-for example, refs $^{101135150}$, adult and scholastic competence ${ }^{88} 151$ locus of control-for example, refs ${ }^{6{ }^{130}}{ }^{152}$, socialisation, ${ }^{153}$ susceptibility to peer influence, ${ }^{84152}$ and risk-taking. ${ }^{154}$ The first four factors appear to be protective against smoking whereas the last two are risk factors.

Johnson and Gilbert ${ }^{37}$ evaluated the ability of several other constructs, including state and trait variables, to distinguish smokers from non-smokers. Trait anger and anxiety variables discriminated smokers from non-smokers, implying that more stable characteristics may be important in adolescent smoking. Forgays et $a l^{155}$ also found trait anxiety and anger to be significantly associated with smoking status. Evans et $a l^{156}$ found sex role predictive of smoking frequency. Religiosity was a protective factor for females and a risk factor for males in predicting smoking frequency. ${ }^{95}$

Not surprisingly, more positive attitudes toward smoking and smokers tended to be related to an increased likelihood of smoking. ${ }^{31} 4591105118157$ McNeill et al, ${ }^{35}$ however, found that beliefs and opinions about smoking did not predict smoking uptake in the presence of sociodemographic, environmental, and behavioural factors, and Charlton and Blair $^{83}$ found the relationship between positive attitudes to smoking and initiation of smoking to be significant only for females. Attitudes may not be as important as other factors; Stanton and Silva ${ }^{89}$ did not find an association after controlling for friends' smoking. Although some studies have found knowledge about the detrimental health effects of smoking to be protective-for example, refs ${ }^{36}{ }^{138}$, the bulk of the literature does not support this position (for example, refs ${ }^{3135158}$ ).

Finally, personal health concerns appear to motivate young smokers as well as adults. Eiser et $a l,{ }^{130}$ for example, found that the importance of health items was related to smoking status; belief that personal health is damaged by smoking was protective for initiation to smoking and for daily smoking. ${ }^{80}$

\section{Discussion and conclusions}

ANALYSIS

Table 1 presents an overall summary of the findings from this review. The rising interest in the identification of predictors of adolescent smoking is demonstrated by the surge at the beginning of this decade in the number of these publications. Some general statements can be made about many of the associations. Most of the factors summarised in each section of the review have been associated with adolescent smoking, as has been shown by other researchers-for example, see reviews by $\mathrm{USDHHS}^{8}$; Flay $^{26}$; Cohen et al ${ }^{159}$; Giovino et al. ${ }^{160}$ Among the variables, only gender shows no association, at least in recent studies and in Western societies. The influence of acculturation, urban/rural residence, availability of tobacco, and coping is unclear and more research is needed to determine their effect. Although the impact of knowledge of the health effects of tobacco is uncertain, several studies appear to demonstrate that this knowledge has no effect; it may become relevant, however, when it is "personalised" by the individual.

There are some variables that have not been considered in this review because of the small amount of evidence available. These include policy-related variables such as price and advertising, ${ }^{161-163}$ and genetic factors. ${ }^{164} \mathrm{Re}-$ search in these areas offers promise in the direction of isolating risk and protective factors, but the potential importance of these variables has yet to be determined.

As noted previously, it is often difficult to synthesise results from the myriad of relevant studies because of the wide variation in methods, measures, and analyses. In addition, outcomes have varied across studies and, even when an outcome is labelled in the same way, the definitions often differ. Therefore, we recommend that standard definitions be adopted in the future-for example, ref $^{11}$. Furthermore, for those individuals who have access to some of the data reported here, re-analysis of the data employing these definitions would add immeasurably to the body of knowledge. It may then be possible to draw definitive conclusions about some of the factors whose effects are currently unclear.

It has been suggested that some of the inconsistencies have arisen because of a cohort effect: changes in the variables that are impor- 
tant for different birth cohorts over time. Given the relatively limited time period covered in this review and the consistency of the results with those in the past, however, it is unlikely that this is a major contributor to the pattern of results observed.

Some authors of reviews have felt it necessary to exclude those investigations which only include cross-sectional data. Such studies were included in this literature review. It is important to note that, where findings were consistent, they were generally found in both types of study designs; where they were not, it did not appear that the different results could be attributed to study design. Hence, the inclusion of all studies, regardless of methods, does not detract from the conclusions reached but instead adds credibility to them.

One issue arising from an examination of the literature concerns the nature of protective and risk factors. Are protective factors more than simply an absence or low level of risk factors? Is it possible that some factors function in one way (as the absence or low level of the factor) and others in an alternate fashion (as the presence of the factor)? As noted in an earlier review, ${ }^{165}$ to develop prevention interventions, it is necessary to understand the functioning of protective and risk factors, their relative importance, and how they interact. There may be some readily modifiable risk factors that could serve as the basis for effective interventions. One such factor is the concern about health effects that are perceived as directly relevant and personal, and that appear to impact on adolescent smoking and uptake as well as on the smoking behaviour of adults. ${ }^{149}$ Why this is so, when knowledge about health effects generally appears to bear little relationship to smoking by young people, is an important area for investigation. It is not readily apparent why health knowledge seems to be generally accepted as important, but yet does not appear to influence behaviour as expected. Future investigations should address this issue as well as questions concerning the functioning of risk/protective factors.

Although it is often assumed that research findings will inevitably be translated into intervention programmes, the data may instead remain within the academic community and fail to be disseminated to experts in programme and policy development. There is material available that could be applied to curriculum development if the lines of communication were open, comprehensible, and used. For example, it is well known and generally accepted that stress and self-esteem are important constructs in many areas, among them substance use/abuse. Why is this information then not routinely used by those individuals who have responsibility for programme development within the schools? It is also accepted that knowledge of health effects alone does not appear to offer protection against smoking; all of us "know", however, that this health information needs to be communicated and so we persist in supporting this approach. Flay $^{26}$ has suggested that interventions need to be multifaceted rather than narrowly focused on only one or two factors. It is clear that interventions also must incorporate research findings. It is essential that experts work together to ensure that the information is translated into programmes, the programmes are implemented and evaluated, and the results are disseminated widely.

PROPOSED THEORETICAL FRAME OF REFERENCE Useful information on the process of initiation to smoking has been gathered from empirical research; there is a need, however, for theory-based research that attempts to synthesise the current body of knowledge and to generate information that will lead to an understanding of the process. If such information is forthcoming, it could serve as the basis for prevention and intervention programmes that will be more successful over the long term than those that have been used to date. Given the complex nature of smoking and the influences affecting it, it is important to consider individual, social, biological, physiological, environmental, and political variables in the development of a model of acquisition (see review by Fisher, Lichtenstein, and Haire-Joshu ${ }^{166}$ ).

One such theoretical model has been examined in a recent study. It incorporates stress, coping, and personal resources as constructs for the "explanation" of initiation to smoking. ${ }^{55}$ This model can be used to explain some of the sociodemographic differences that have been consistently noted in the literature and has, as its basis, empirical information from the literature on smoking among adults, on factors related to initiation and maintenance of adolescent smoking, and on variables associated with initiation to other substance use. In this model, we have attempted to integrate these findings and to address factors which are potentially modifiable. Hence, research using such a model may yield interventions, based on the complex multifaceted nature of smoking, that may reduce the likelihood of smoking.

Smoking probably serves different functions for males and females (for a review, see Clayton $^{27}$ ). The model outlined allows in-depth examination of the possible mechanisms operating at various times in the development and maintenance of smoking. Preliminary data from our own research ${ }^{55}$ provide support for this approach and document different possible functions of smoking.

One of the most consistent findings in the literature is that of the social influence of peers and others on adolescent smoking. Modelling, direct pressure, and normative beliefs ${ }^{167}$ have been suggested as mechanisms of influence and investigated along with the potential importance of levels of social interactions, as suggested in the works of Eiser et $a l^{157}$ and Sussman et $a .^{115}$ Of particular interest is research suggesting that initiation to smoking is best modelled as a prevalence-driven behaviour depending upon the degree to which an adolescent comes in contact with others displaying the behaviour. ${ }^{168}$ The maintenance 
of smoking, on the other hand, shows a degree of independence from prevalence. ${ }^{103}$

Because network data and analysis yield methods of measuring and systematising the concept of social context, as well as provide information on the association of social context variables with behaviour (see review by Bauman and Ennett ${ }^{107}$ ), they may contribute to understanding variability in smoking prevalence and thus help to determine the salience of stress-coping mechanisms. Integration of this network research with data specified in the conceptual model described above would provide the opportunity to examine personal behaviour in a social context.

\section{Recommendations}

- Attempts should be made to use standard definitions of outcome and predictor variables. When available and appropriate, previously validated scales should also be used.

- Analyses should include multivariate and bivariate models, with some attempt in the multivariate models to test specific hypotheses based on findings from the literature and from theory.

- Future research should be theory driven and consider the range of possible factors, such as social, personal, economic, environmental, biological, and physiological influences, that may influence smoking behaviour.

- Research teams should include representatives from a broad spectrum of disciplines, particularly educators and programme providers, so that the information gathered is potentially useful in the identification of high risk groups and the design of interventions.

- Investigations focused on determining whether protective and risk factors are at opposite ends of the same dimension, or are qualitatively and functionally different, should be supported.

- The apparent inconsistencies in relationships between parental SES and adolescent disposable income need to be resolved. Another priority area is clarification of the relevant underlying constructs for which SES is a proxy. Although it is accepted that education, occupation, and income are components of SES, further research is required to determine what social and other factors operate within various groups to produce differences in smoking behaviour.

This research was made possible in part by Health Canada through a National Health Research and Development Programme (NHRDP) Research Training Award to Suzanne Tyas. The constructive comments made by Dr Gene McGrady are appreciated.

1 Millar WJ. The smoking behavior of Canadians 1986. Ottawa, Canada: Health and Welfare Canada, Health Services and Promotion Branch, 1987.

2 Pederson LL. Smoking. In: Stephens T, Graham D, eds. Canada's Health Promotion Survey 1990: technical report. Ottawa, Canada: Minister of Supply and Services Canada, 1993: 91-101.

3 Statistics Canada. Health status of Canadians: report of the 1991 General Social Survey. Ottawa, Canada: Ministry of Industry, Science and Technology, 1994. (Catalogue No Industry, Science

4 Statistics Canada. Survey on smoking in Canada, cycle 1 through cycle 4. Ottawa, Canada: Special Surveys Division, June 1995.
5 Millar WJ. Smoking prevalence among Canadian adolescents: a comparison of survey estimates. Can $\mathcal{F}$ Public

6 Smart RG, Adlaf EM. Alcohol, cannabis, cocaine and other drug use among Ontario students in 1987, and trends since 1977. Toronto, Canada: Addiction Research Foundation, 1988.

7 Smart RG, Adlaf EM. The Ontario Student Drug Use Survey: trends between 1977-1989. Toronto, Canada: Addiction Research Foundation, 1989.

8 US Department of Health and Human Services. Preventing tobacco use among young people. A report of the Surgeon General, 1994. Atlanta, Georgia: Public Health Service, Centand Health, 1994. (US Government Printing Office Publication No S/N 017-001-00491-0.)

9 Greaves L. Background paper on women and tobacco. Ottawa, Canada: Health and Welfare Canada, Health Promotion Directorate, 1987.

10 Decima Research. Pepsi/YTV Street Beat: a teen poll. A nationwide survey of Canadian teens. Toronto, Canada: Decima Research, 1991

11 Stephens T, Morin M, eds. (with Health Canada). Youth Smoking Survey, 1994: technical report. Ottawa, Canada: Minister of Supply and Services Canada, 1996.

12 Coambs RS, Seline L, Kozlowski LT. Age interacts with heaviness of smoking in predicting success in cessation of smoking. Am 7 Epidemiol 1992;135:240-6.

13 Breslau N, Peterson EL. Smoking cessation in young adults: age at initiation of cigarette smoking and other suspected age at initiation of cigarette smoking and other
influences. Am f Public Health 1996;86:214-20.

14 Chassin L, Presson CC, Sherman SJ, et al. The natural history of cigarette smoking: predicting young-adult smoking outcomes from adolescent smoking patterns. Health Psychol 1990;9:701-16.

15 Pierce JP, Gilpin E. How long will today's new adolescent smoker be addicted to cigarettes? Am $\mathcal{f}$ Public Health 1996;86:253-6.

16 Evans RI, Roaelle RM, Maxwell SE, et al. Social modelling films to deter smoking in adolescents: results of a three-year field investigation. F Appl Psychol 1981;66:319414 .

17 Luepker RV, Johnson CA, Murray DM, et al. Prevention of cigarette smoking: three-year follow-up of an education program for youth. $\mathcal{F}$ Behav Med 1983;6:53-62.

18 Flay BR. Psychosocial approaches to smoking prevention: a review of findings. Health Psychol 1985;4:449-88.

19 Johnson CA, Hansen WB, Collins LM, et al. High-school smoking prevention: results of a three-year longitudinal study. F Behav Med 1986;9:439-52.

20 Murray DM, Davis-Hearn M, Goldman AI, et al. Four and five-year follow-up results from four seventh-grade smoking prevention strategies. F Behav Med 1988;11:395-405.

21 Flay BR, Koepke D, Thamson SJ, et al. Six year follow-up of the first Waterloo smoking prevention trial. Am f Public Health 1989;79:1377-80.

22 Ajzen I, Fishbein M. The prediction of behavior from attitudinal and normative variables. F Exp Soc Psychol 1970; 6:466-87.

23 Bandura A. Social learning theory. Englewood Cliffs, New Jersey: Prentice Hall, 1977.

24 Jessor R, Jessor SL. Problem behavior and psychosocial development: a longitudinal study of youth. New York: Academic Press, 1977

25 Rosenberg M. Conceiving the self. New York: Basic Books, 1979.

26 Flay BR. Youth tobacco use: risks, patterns, and control. In: Orleans CT, Slade J., eds. Nicotine addiction: principles and management. New York: Oxford University Press, 1993:365-84.

27 Clayton S. Gender differences in psychosocial determinants of adolescent smoking. $\mathcal{F}$ Sch Health 1991;61:115-20.

28 Conrad KM, Flay BR, Hill, D. Why children start smoking cigarettes: predictors of onset. Br F Addict 1992;87:1711-

29 Newcomb MD. Identifying high-risk youth: prevalence and patterns of adolescent drug abuse. In: Rahdert E, Czechowicz D, eds. Adolescent drug abuse: clinical assessment and therapeutic interventions. Rockville, Maryland: US Department of Health and Human Services, NIDA Research Monograph 156, 1995:7-38

30 Wang S-Q, Yu J-J, Zhu B-P, et al. Cigarette smoking and its risk factors among senior high school students in Beijing, China, 1988. Tobacco Control 1994;3:107-14.

31 Botvin GJ, Baker E, Goldberg CJ, et al. Correlates and predictors of smoking among Black adolescents. Addict Behav 1992;17:97-103.

32 Dusenbury L, Kerner JF, Baker E, et al. Predictors of smoking prevalence among New York Latino Youth. Am f Public Health 1992;82:55-8.

33 Camp DE, Klesges RC, Relyea G. The relationship between body weight concerns and adolescent smoking. Health Psychol 1993;12:24-32.

34 Escobedo LG, Marcus SE, Holtzman D, et al. Sports participation, age at smoking initiation, and the risk of smoking among US high school students. $7 A M A$ 1993; 269:1391-5.

35 McNeill AD, Jarvis MJ, Stapleton JA, et al. Prospective study of factors predicting uptake of smoking in adolescents. F Epidemiol Commun Health 1988;43:72-8.

36 Tuakli N, Smith MA, Heaton C. Smoking in adolescence: methods for health education and smoking cessation. A MIRNET study. F Fam Pract 1990;31:369-74. 
37 Johnson EH, Gilbert D. Familial and psychological correlates of smoking in Black and White adolescents. Ethcorrelates of smoking in B
nicity Dis 1991;1:320-34.

38 Oakley A, Brannen J, Dodd K. Young people, gender and smoking in the United Kingdom. Health Promotion In 1992;7:75-88.

39 McGee R, Stanton WR. A longitudinal study of reasons for smoking in adolescence. Addiction 1993;88:265-71.

40 Stanton WR, Oei TPS, Silva PA. Sociodemographic characteristics of adolescent smokers. Int f Addict 1994;29:91325.

41 Ogawa H, Tominaga S, Gellert G, et al. Smoking among junior high school students in Nagoya, Japan. Int $\mathcal{F}$ Epidemiol 1988;17:814-20.

$42 \mathrm{Hu}$ J, Liu R, Zhang H, et al. A survey of cigarette smoking among middle scho

1990;104:345-51. Mendis S. Tobacco use in a coth
Br $\mathcal{F}$ Addict 1990;85:397-8.

44 Chen Y, Pederson LL, Lefcoe NM. Father's educational level, adult's smoking status, and children's smoking behavior

45 Zhu B-P, Liu M, Shelton D, et al. Cigarette smoking and its risk factors among elementary school students in Beijing. Am F Public Health 1996;86:368-75.

46 Wiecha JM. Differences in patterns of tobacco use in Vietnamese, African-American, Hispanic, and Caucasian adolescents in Worcester, Massachusetts. Am $\mathcal{F}$ Prev Med 1996;12:29-37.

47 Pan American Health Organization. World Health Organisation, Tobacco or Health: status in the Americas. A report of the Pan American Health Organization. Washington, DC: Pan American Health Organization, 1992.

48 US Department of Health and Human Services. Smoking and health in the Americas: a 1992 report of the Surgeon General in collaboration with the Pan American Health Organization. Atlanta, Georgia: Centers for Disease Control, Office tion. Atlanta, Georgia: Centers for Disease Control, Office
on Smoking and Health, 1992. (DHHS Publication No on Smoking and He

49 Mackay J. The state of health atlas. Touchstone, New York: Simon and Schuster, 1993.

50 Boyle MH, Szatmari P, Offord DR, et al. Substance use among adolescents and young adults: prevalence, sociodemographic correlates, associated problems and familial aggregation. Ontario Health Survey 1990: Working Paper No 2. Toronto, Canada: Ontario Ministry of Health, 1993.

51 Thorlindsson T, Vilhjalmsson R. Factors related to cigarette smoking and alcohol

52 Isohanni M, Moilanen I, Rantakallio P. Determinants of teenage smoking, with special reference to non-standard family background. Br 7 Addict 1991;86:391-8.

53 Pederson LL. Change in variables related to smoking from childhood to late adolescence: an eight year longitudinal study of a cohort of elementary school students. Can $\mathcal{F}$ Public Health 1986;77(suppl 1):33-9.

54 Pederson LL, Lefcoe NM. Change in smoking status among a cohort of late adolescents: prediction and explanation of initiation, maintenance and cessation. Int $\mathcal{F}$ Epidemiol 1986;15:519-26

55 Koval JJ, Pederson LL. Stress-coping and other psychosocial risk factors: a model for smoking in Grade 6 students. Working Papers Series No 19. Toronto, Canada: Ontario Tobacco Research Unit, 1996.

56 Bachman JG, Wallace JM Jr, O'Malley PM, et al. Racial/ethnic differences in smoking, drinking, and illicit drug use among American high school seniors. Am F Public Health 1991;81:372-7.

57 Gfellner BM. A matched-group comparison of drug use and problem behavior among Canadian Indian and White adolescents. 7 Early Adolesc 1994;14:24-48.

58 McDermott RJ, Sarvela PD, Hoalt PN, et al. Multiple correlates of cigarette use among high school students. F Sch Health 1992;62:146-50

59 Kann L, Warren CW, Collins JL, et al. Results from the national school-based 1991 Youth Risk Behavior Survey and progress toward achieving related health objectives for
the nation. Public Health Reports 1993;108(suppl 1):47-55.

60 Headen SW, Bauman KE, Deane GD, et al. Are the correlates of cigarette smoking initiation different for Black and White adolescents? Am $f$ Public Health 1991;81:854-8.

61 Vega WA, Zimmerman RS, Warheit GJ, et al. Risk factors for early adolescent drug use in four ethnic and racial groups. Am 7 Public Health 1993;83:185-9.

62 Vega WA, Gil AG, Zimmerman RS. Patterns of drug use among Cuban-American, African-American, and White non-Hispanic boys. Am f Public Health 1993;83:257-9.

63 Landrine H, Richardson JL, Klonoff EA, et al. Cultural diversity in the predictors of adolescent cigarette smoking: the relative influence of peers. F Behav Med 1994;17:33146.

64 Covey LS, Tam D. Depressive mood, the single-parent home, and adolescent cigarette smoking. Am f Public Health 1990;80:1330-3.

65 Turner RA, Irwin CE Jr, Millstein SG. Family structure, family processes, and experimenting with substances during adolescence. $\mathcal{F}$ Res Adolesc 1991;1:93-106.

66 Botvin GJ, Baker E, Botvin EM, et al. Factors promoting cigarette smoking among Black youth: a causal modeling approach. Addict Behav 1993;18:397-405.

67 Burchfiel CM, Higgins MW, Keller JB, et al. Initiation of cigarette smoking in children and adolescents of Tecumseh, Michigan. Am F Epidemiol 1989;130:410-5.
68 Millar WJ, Hunter L. The relationship between socioeconomic status and household smoking patterns in Canada. Am $\mathcal{F}$ Health Promotion 1990;5:36-43.

69 Pedersen W, Lavik NJ. Role modelling and cigarette smoking: vulnerable working class girls? Scand f Soc Med 1991;19:110-5.

70 Bauman KE, Foshee VA, Linzer MA, et al. Effect of parental smoking classification on the association between parental and adolescent smoking. Addict Behav 1990; 15:413-22.

71 Shibata A, Fukuda K, Hirohata T. Smoking habits among senior high school students and related factors. Kurume Med f 1990;37:129-40.

72 Hammarström A, Janlert U. Unemployment and change of tobacco habits: a study of young people from 16 to 21 tobacco habits: a study of young people

73 Blackford KA, Bailey PH, Coutu-Wakulczyk GM. Tobacco use in northeastern Ontario teenagers: prevalence of use and associated factors. Can $\mathcal{F}$ Public

74 Noland MP, Kryscio RJ, Riggs RS, et al. Use of snuff, chewing tobacco, and cigarettes among adolescents in tobacco-producing area. Addict Behav 1990;15:517-30.

75 Cresswell WH, Huffman WJ, Stone DB. Youth smoking: behavior characteristics and their educational implications. A report of the University of Illinois Anti-Smoking Educa

76 Newman IM, Ward JM. The influence of parental attitude and behavior on early adolescent cigarette smoking. $\mathcal{F} \mathrm{Sch}$ Health 1989;59:150-2.

77 Biglan A, Duncan TE, Ary DV, et al. Peer and parental influences on adolescent tobacco use. F Behav Med 1995; 8:315-30.

78 Krohn MD, Massey JL, Zielinski M. Role overlap, network multiplexity, and adolescent deviant behavior. Soc Psychol $Q$ 1988;51:346-56

79 Reimers TM, Pomrehn PR, Becker SL, et al. Risk factors for adolescent cigarette smoking: the Muscatine study. $\operatorname{Am} \mathcal{F}$ Dis Child 1990;144:1265-72.

80 Jensen EJ, Overgaard E. Investigation of smoking habits among 14-17-year-old boarding school pupils: factors which influence smoking status. Public Health 1993; 107:117-23.

81 Hover SJ, Gaffney LR. Factors associated with smoking behavior in adolescent girls. Addict Behav 1988;13:13945 .

82 Hops H, Tildesley E, Lichtenstein E, et al. Parentadolescent problem-solving interactions and drug use. $\mathrm{Am}$ adolescent problem-solving interactions
f Drug Alcohol Abuse 1990;16:239-58.

83 Charlton A, Blair V. Predicting the onset of smoking in boys and girls. Soc Sci Med 1989;29:813-8.

84 Swan AV, Creeser R, Murray M. When and why children first start to smoke. Int F Epidemiol 1990;19:323-30.

85 Green G, Macintyre S, West P, et al. Like parent like child? Associations between drinking and smoking behaviour of parents and their children. Br f Addict 1991;86:745-58.

86 Quine S, Stephenson JA. Predicting smoking and drinking intentions and behavior of pre-adolescents: the influence of parents, siblings, and peers. Fam Sys Med 1990;8:191200.

87 Botvin GJ, Epstein JA, Schinke SP, et al. Predictors of cigarette smoking among inner-city minority youth. Dev Behav Pediatr 1994;15:67-73.

88 Minagawa K-E, While D, Charleton A. Smoking and self-perception in secondary school students. Tobacco Control 1993;2:215-21.

89 Stanton WR, Silva PA. Children's exposure to smoking. Int F Epidemiol 1991;20:933-7.

90 Santi S, Best J, Brown KS, et al. Social environment and smoking initiation. Int $\mathcal{F}$ Addict 1990-1991;25:881-903.

91 Meier KS. Tobacco truths: the impact of role models on children's attitudes toward smoking. Health Educ Q 1991; 18:173-82.

92 Emmanuel SC, Ho CK, Chen AJ. Cigarette smoking among school children in Singapore. Part II. development of the smoking habit. Singapore Med f 1991;32:146-50.

93 Richardson JL, Dwyer K, McGuigan K, et al. Substance use among eighth-grade students who take care of themselves after school. Pediatrics 1989;84:556-66.

94 Farrell AD, Danish SJ, Howard CW. Risk factors for drug use in urban adolescents: identification and
validation. Am f Commun Psychol 1992;20:263-86.

95 Krohn MD, Naughton MJ, Skinner WF, et al. Social disaffection, friendship patterns and adolescent cigarette use: the Muscatine study. $\mathcal{F}$ Sch Health 1986;56:146-50.

96 Cohen DA, Richardson J, LaBree L. Parenting behaviors and the onset of smoking and alcohol use: a longitudinal study. Pediatrics 1994;94:368-75.

97 Foshee V, Bauman KE. Parental attachment and adolescent cigarette smoking initiation. F Adolesc Res 1994;9:88-104. 98 Wills TA, Vaughan R. Social support and substance use in early adolescence. $\mathcal{F}$ Behav Med 1989;12:321-39.

99 Foshee V, Bauman KE. Parental and peer characteristics as modifiers of the bond-behavior relationship: an elaboration of control theory. F Health Soc Behav 1992;33:66-76.

100 Melby JN, Conger RD, Conger KJ, et al. Effects of parental behavior on tobacco use by young male adolescents. $\mathcal{F}$ Marriage Fam 1993;55:439-54.

101 Jackson C, Bee-Gates DJ, Henriksen L. Authoritative parenting, child competencies, and initiation of cigarette parenting, child competencies, and initiatio

102 Block J, Block JH, Keyes S. Longitudinally foretelling drug usage in adolescence: early childhood personality and environmental precursors. Child Dev 1988;59:336-55. 
103 Morgan M, Grube JW. Closeness and peer group influence. Br F Soc Psychol 1991:30:159-69.

104 Hirschman RS, Leventhal H, Glynn K. The development of smoking behavior: conceptualization and supportive cross-sectional survey data. F Appl Soc Psychol 1984; 14:184-206.

105 Spear SF, Akers RL. Social learning variables and the risk of habitual smoking among adolescents: the Muscatine study. Am $\mathcal{F}$ Prev Med 1988;4:336-42.

106 Ennett ST, Bauman KE. Peer group structure and adolescent cigarette smoking: a social network analysis. 7 Health Soc Behav 1993;34:226-36.

107 Bauman KE, Ennett ST. On the importance of peer influence for adolescent drug use: commonly neglected considerations. Addiction 1996;91:185-98.

108 Aloise-Young PA, Graham JW, Hansen WB. Peer influence on smoking initiation during early adolescence: a comparison of group members and group outsiders. $\mathcal{F}$ Appl Psychol 1994;79:281-7.

109 Urberg KA, Shyu S-J, Liang J. Peer influence in adolescent cigarette smoking. Addict Behav 1990;15:247-55.

110 Botvin GJ, Botvin EM, Baker E, et al. The false consensus effect: predicting adolescents' tobacco use from normative expectations. Psychol Rep 1992;70:171-8.

111 Graham JW, Marks G, Hansen WB. Social influence processes affecting adolescent substance use. 7 Appl Psychol 1991;76:291-8.

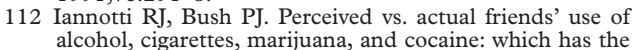
most influence? F Youth Adolesc 1992;21:375-89.

113 DiFranza JR, Savageau JA, Aisquith BF. Youth access to tobacco: the effects of age, gender, vending machine locks, and "It's the Law" programs. Am $\mathcal{f}$ Public Health 1996;86:221-4

114 Allison KR. Academic stream and tobacco, alcohol, and cannabis use among Ontario high school students. Int $\mathcal{F}$ Addict 1992;27:561-70.

115 Sussman S, Dent CW, Stacy AW, et al. Peer-group association and adolescent tobacco use. F Abnormal Psychol 1990 99:349-52.

116 McDonough P, Rootman I, Corey P, Ferrence R. Interrelations among health behaviours. Working Paper No 4, Ontario Health Survey 1990. Toronto, Canada: Ontario Ministry of Health, 1993.

117 Hawkins WE. Problem behaviors and health-enhancing practices of adolescents: a multivariate analysis. Health Values 1992;16:46-54

118 Lo SK, Blaze-Temple D, Binns CW, et al. Adolescent cigarette consumption: the influence of attitudes and peer drug use. Int $\mathcal{F}$ Addict 1993;28:1515-30.

119 Thorlindsson T, Vilhjalmsson R, Valgeirsson G. Sport participation and perceived health status: a study of ticipation and perceived health status:

120 Chassin LA, Presson CC, Sherman SJ. Cigarette smoking and adolescent psychosocial development. Basic Appl Soc Psychol 1984;5:295-315.

121 Chassin L, Presson CC, Sherman SJ. Cognitive and social influence factors in adolescent smoking cessation. Addict Behav 1984;9:383-90.

122 Glynn KG, Leventhal H, Hirschman RS. A cognitive developmental approach to smoking prevention. In: Bell CS, Battjes RT, eds. Prevention research: deterring drug abuse among children and adolescents. National Institute on Drug Abuse Research Monograph 63. Washington, DC: US Government Printing Office, 1985:130-52.

123 Hawkins JD, Lishner D, Catalano RF Jr. Childhood predictors and the prevention of substance abuse. In: Bell CS, Battjes RT, eds. Prevention research: deterring drug abuse among children and adolescents. National Institute on Drug among children and adolescents. National Institute on Drug Abuse Research Monograph 63. Washingto
ernment Printing Office, 1985:76-126.

124 Pentz MA. Social competence and self-efficacy as determinants of substance use in adolescence. In: Shiffman S, Wills TA, eds. Coping and substance abuse. New York: Academic Press, 1985:117-42.

125 Wills TA. Stress, coping and tobacco and alcohol use. In Shiffman S, Wills TA, eds. Coping and substance abuse. New York: Academic Press, 1985:63-94.

126 Wills TA. Stress and coping in early adolescence: relationships to substance use in urban school samples. Health Psychol 1986;5:503-29.

127 Baer PE, McLaughlin RJ, Burnside MA, et al. Stress, the family environment and multiple substance use among seventh graders. Psychol Addict Behav 1987;1:92-103.

128 Castro FG, Maddahian E, Newcomb MD, et al. A multivariate model of the determinants of cigarette smok89 .

129 Jessor R. Problem-behavior theory, psychosocial development, and adolescent problem drinking. Br f Addict 1987; 82:331-42.

130 Eiser JR, Eiser C, Gammage P, et al. Health locus of control and health beliefs in relation to adolescent smoking. $B$ f Addict 1989;84:1059-65.

131 Shedler J, Block J. Adolescent drug use and psychological health: a longitudinal inquiry. Am Psychol 1990;45:61230.

132 Zuckerman M, Ball S, Black J. Influences of sensation seeking, gender, risk appraisal, and situational motivation on smoking. Addict Behav 1990;15:209-20.

133 Wills TA, Shiffman S. Coping and substance use: a conceptual framework. In: Shiffman S, Wills TA, eds. Coping and substance abuse. New York: Academic Press, 1985:3-24.
134 McAlpine D, Pederson LL. Tobacco use during adolescence: assessing the roles of stressful life events and psychosocial
resources. Unpublished manuscript, The University of resources. Unpublished manuscript, The

135 Bonaguro JA, Bonaguro EW. Self-concept, stress symptomatology, and tobacco use. F Sch Health 1987;57:56-8.

36 Reppucci JD, Revenson TA, Aber M, et al. Unrealistic optimism among adolescent smokers and nonsmokers. $\mathcal{F}$ Primary Prev 1991;11:227-36.

137 Byrne DG, Byrne AE, Reinhart MI. Personality, stress and the decision to commence cigarette smoking in adolescence. F Psychosom Res 1995;39:53-62.

138 Prokhorov AV, Alexandrov AA. Tobacco smoking in Moscow school students. Br f Addict 1992;87:1469-76.

139 Wang MQ, Fitzhugh EC, Westerfield RC, et al. Predicting smoking status by symptoms of depression for US adolescents. Paper presented at the meeting of the American cents. Paper presented at the meeting of the American October 1993.

140 Leventhal H, Cleary PD. The smoking problem: a review of research and theory. Psychol Bull 1980;88:370-405.

41 Yeaworth RC, York J, Hussey MA, et al. The development of an adolescent life change event scale. Adolescence 1980; 15:93-7.

142 Abrams DB. Alcohol and stress interaction. In: Pohoreck LA, Brick J, eds. Stress and alcohol use. New York: Elsevier, 1983:61-86.

143 Fleming R, Baum A, Singer JE. Toward an integrative approach to the study of stress. F Personality Soc Psychol 1984:46:939-49.

144 Marlatt GA, Gordon JR. Relapse prevention: maintenance strategies in the treatment of addictive behaviours. New York: Guilford Press, 1985

145 Mates D, Allison KR. Sources of stress and coping responses of high school students. Adolescence 1992; 27:461-74.

146 Pearlin LI, Schooler C. The structure of coping. F Health Soc Behav 1978;19:2-21.

147 Pearlin LI, Lieberman MA, Managhan EG, et al. The stress process. F Health Soc Behav 1981;22:337-56.

148 Shiffman S, Wills TA. Coping and substance abuse. New York: Academic Press, 1985

149 Pederson LL, Koval JJ, O’Connor K. Are psychosocial factors related to smoking in Grade 6 students? Addict Behav 1997;22:169-81.

150 Young M, Werch CE. Relationship between self-esteem and substance use among students in fourth through twelfth grade. Wellness Persp Res Theory Pract 1990;7:3144.

151 Wills TA, Vaccaro D, McNamara G. The role of life events, family support, and competence in adolescent substance use: a test of vulnerability and protective factors. $A m \mathcal{F}$ Commun Psychol 1992;20:349-74.

152 Dielman TE, Campanelli PC, Shope JT, et al. Susceptibility to peer pressure, self-esteem, and health locus of control as correlates of adolescent substance abuse. Health Educ Q 1987;14:207-21.

153 Bush PJ, Iannotti RJ. Elementary schoolchildren's use of alcohol, cigarettes and marijuana and classmates' attribualcohol, cigarettes and marijuana and classmates' attribu-
tion of socialization. Drug Alcohol Depend 1992;30:275-87.

154 Simon TR, Sussman S, Dent CW, et al. Prospective correlates of exclusive or combined adolescent use of cigarettes and smokeless tobacco: a replication-extension. Addict Behav 1995;20:517-24.

155 Forgays DG, Forgays DK, Wrzesniewski K, et al. Personality dimensions and cigarette smoking behavior in Polish and US adolescents. Psychol Health 1993;8:257-68.

156 Evans RI, Turner SH, Ghee KL, et al. Is androgynous sex role related to cigarette smoking in adolescents? F Appl Soc Psychol 1990;20:494-505.

157 Eiser JR, Morgan M, Gammage P, et al. Adolescent health behaviour and similarity-attraction: friends share smoking habits (really), but much else besides. Br 7 Soc Psychol 1991;30:339-48.

158 Virgili M, Owen N, Severson HH. Adolescents' smoking behavior and risk perceptions. F Substance Abuse 1991; 3:315-24.

159 Cohen J, Ferrence R, Jackson L, et al. Gender differences in the predictors of the acquisition of smoking by adolescents. Literature Reviews Series No 5. Toronto, Canada: Ontario Tobacco Research Unit, 1996.

160 Giovino GA, Henningfield JE, Tomar SL, et al. Epidemiology of tobacco use and dependence. Epidemiol Rev

161 Pentz MS, Sussman S, Newman T. The conflict between least harm and no-use tobacco policy for youth: ethical and policy implications. Addiction 1997;92:1165-73.

162 Wolfson M, Hourigan M. Unintended consequences and professional ethics: criminalization of alcohol and tobacco use by youth and young adults. Addiction 1997;92:115964.

163 Pierce JP, Choi WS, Gilpin EA, et al. Tobacco industry promotion of cigarettes and adolescent smoking. $\mathcal{F} A M A$ 1998;279:511-5.

164 Pomerleau, O. First dose experiences with nicotine: exploring the phenotype for smoking. Presentation at the 4th Annual Meeting of the Society for Research in Nicotine and Tobacco, New Orleans, Louisiana, March 1998.

165 Hawkins JD, Catalano RF, Miller JY. Risk and protective factors for alcohol and other drug problems in adolescence and early adulthood: implications for substance abuse prevention. Psychol Bull 1992;112:64-105. 
166 Fisher EB, Lichtenstein E, Haire-Joshu D. Multiple determinants of tobacco use and cessation. In: Orleans CT, Slade J, eds. Nicotine addiction: principles and manage

167 Urberg KA. Locus of peer influence: social crowd and best friend. F Youth Adolesc 1992;21:439-50.

168 Rowe DC, Chassin L, Presson CC, et al. An "epidemic" model of adolescent cigarette smoking. $\mathcal{F}$ Appl Soc Psychol 1992;22:261-85.

Related references

(Reviewed and summarised in detailed tables, but not cited in text)

69 Abernathy TJ, Massad L, Romano-Dwyer L. The relationships between smoking and self-esteem. Adolescence 1995; 30:899-907.

170 Allen O, Page RM, Moore L, et al. Gender differences in selected psychosocial characteristics of adolescent smokers and nonsmokers. Health Values 1994;18:34-9.

171 Bates ME, Pandina RJ. Individual differences in the stability of personality needs: relations to stress and substance use during adolescence. Personality and Individual Differences 1989;10:1151-7.

172 Bates ME, Pandina RJ. Personality stability and adolescent substance use behaviors. Alcoholism Clin Exp Res 1991; 15:471-7.

173 Bauman KE, Botvin GJ, Botvin EM, et al. Normative expectations and the behavior of significant others: an integration of traditions in research on adolescents' cigarette smoking. Psychol Rep 1992;71:568-70.

174 Bauman KE, Foshee VA, Haley NJ. The interactions of sociological and biological factors in adolescent cigarette smoking. Addict Behav 1992;17:459-67.

175 Bettes BA, Dusenbury L, Kerner J, et al. Ethnicity and psychosocial factors in alcohol and tobacco use in adolescence. Child Dev 1990;61:557-65.

176 Botvin EM, Botvin GJ, Michela JL, et al. Adolescent smoking behavior and the recognition of cigarette advertisements. F Appl Soc Psychol 1991;21:919-32.

177 Botvin GJ, Goldberg CJ, Botvin EM, et al. Smoking behavior of adolescents exposed to cigarette advertising. Public Health Rep 1993;108:217-24.

178 Brindis C, Wolfe AL, McCarter V, et al. The associations between immigrant status and risk-behavior patterns in between immigrant status and risk-behavior pattern

179 Bush PJ, Ianotti RJ. Alcohol, cigarette, and marijuana use among fourth-grade urban school children in 1988/89 and 1990/91. Am f Public Health 1993;83:111-5.

180 Chassin L, Presson CC, Sherman SJ, et al. Parent educational attainment and adolescent cigarette smoking. f Substance Abuse 1992;4:219-34.

181 Chassin L, Presson CC, Sherman SJ, et al. The natural history of cigarette smoking and young adult social roles. $\mathscr{F}$ Health Soc Behav 1992;33:328-47.

182 de Moor C, Cookson K, Elder JP, et al. The association between teacher attitudes, behavioral intentions, and smoking and the prevalence of smoking among seventhgrade students. Adolescence 1992;27:565-78.

183 Dinh KT, Sarason IG, Peterson AV, et al. Children's perceptions of smokers and nonsmokers: a longitudinal perceptions of smokers and nonsm

184 Ellickson PL, Hays RD. On becoming involved with drugs: modeling adolescent drug use over time. Health Psychol 1992;11:377-85.

185 Farrow JA, Schwartz RH. Adolescent drug and alcohol usage: a comparison of urban and suburban pediatric practices. F Natl Med Assoc 1992;84:409-13.

186 Ferguson KJ, Burke JA, Becker SL, et al. The recruitment of new smokers by adolescents. Health Commun 1992; 4:171-81.

187 Fergusson DM, Horwood LJ. Transitions to cigarette smoking during adolescence. Addict Behav 1995;20:62742 .

188 Fergusson DM, Lynskey MT, Horwood LJ. The role of peer affiliations, social, family and individual factors in continuities in cigarette smoking between childhood and adolescence. Addiction 1995;90:647-59.

189 Flay BR, Hu FB, Siddiqui O, et al. Differential influence of parental smoking and friends' smoking on adolescent initiation and escalation of smoking. F Health Soc Behav 1994;35:248-65.

190 Fournet GP, Estes RE, Martin GL, et al. Drug attitudes and usage among elementary and secondary students. $\mathscr{F}$ Alcohol Drug Educ 1990:35:81-92.

191 French SA, Perry CL, Leon GR, et al. Weight concerns, dieting behavior, and smoking initiation among adolescents: a prospective study. Am F Public Health 1994 84:1818-20.

192 Green G, Macintyre S, West P, et al. Do children of lone parents smoke more because their mothers do? Br f Addict 1990;85:1497-1500.

193 Greening L, Dollinger SJ. Adolescent smoking and perceived vulnerability to smoking-related causes of death. FPediatr Psychol 1991;16:687-99.

194 Grunbaum JA, Basen-Engquist K. Comparison of health risk behaviors between students in a regular high school and students in an alternative high school. I Sch Health 1993;63:421-5.

195 Hansen WB, Graham JW, Sobel JL, et al. The consistency of peer and parent influences on tobacco, alcohol, and marijuana use among young adolescents. I Behav Med 1987;10:559-79.

196 Hunter SM, Vizelberg IA, Berenson GS. Identifying mechanisms of adoption of tobacco and alcohol use among youth: the Bogalusa heart study. Soc Networks 1991;13:91-104

197 Koepke D, Flay BR, Johnson CA. Health behaviors in minority families: the case of cigarette smoking. Fam Commun Health 1990;13:35-43.

198 Kok G, de Vries H, Mudde AN, et al. Planned health education and the role of self-efficacy: Dutch research. Health Educ Res Theory Pract 1991;6:231-8.

199 Labouvie EW, McGee CR. Relation of personality to alcohol and drug use in adolescence. $\mathcal{F}$ Consult Clin Psychol 1986;54:289-93.

200 Lalinec-Michaud M, Subak ME, Ghadirian AM, et al. Substance misuse among native and rural high school students in Quebec. Int $\mathcal{F}$ Addict 1991;26:1003-12.

201 Lawrance L, Rubinson L. Self-efficacy as a predictor of smoking behavior in young adolescents. Addict Behav 1986;11:367-82.

202 McInman AD, Grove JR. Multidimensional self-concept, cigarette smoking, and intentions to smoke in adolescents. Aust Psychol 1991;26:192-6.

203 Millar WJ, Hunter L. Household context and youth smoking behaviour: prevalence, frequency and tar yield. Can $\mathcal{F}$ Public Health 1991;82:83-5.

204 Oleckno WA, Blacconiere MJ. A multiple discriminant analysis of smoking status and health-related attitudes and behaviors. Am f Prev Med 1990;6:323-9.

205 Olmstead RE, Guy SM, O'Malley PM, et al. Longitudinal assessment of the relationship between self-esteem, fatalism, loneliness, and substance use. F Soc Behav Personality 1991;6:749-70.

206 Øygard L, Klepp, K-I, Tell GS, et al. Parental and peer influences on smoking among young adults: ten-year follow-up of the Oslo youth study participants. Addiction 1995;90:561-9.

207 Patton GC, Hibbert M, Rosier MJ, et al. Is smoking associated with depression and anxiety in teenagers? $\mathrm{Am} \mathcal{F}$ Public Health 1996;86:225-30.

208 Pierce JP, Lee L, Gilpin EA. Smoking initiation by adolescent girls, 1944 through 1988: an association with targeted advertising. FAMA 1994;271:608-11.

209 Presti DE, Ary DV, Lichtenstein E. The context of smoking initiation and maintenance: findings from interviews with youths. F Substance Abuse 1992;4:35-45.

210 Sarason IG, Mankowski ES, Peterson AV Jr, et al. Adolescents' reasons for smoking. F Sch Health 1992;62:185-90.

211 Schifano F, Forza G, Gallimberti L. Smoking habit and psychological distress in adolescent female students. $A m \mathcal{F}$ Addict 1994;3:100-5.

212 Skinner WF, Krohn MD. Age and gender differences in a social process model of adolescent cigarette use. Sociol Inquiry 1992;62:56-82.

213 Stanton WR, Silva PA. A longitudinal study of the influence of parents and friends on children's initiation of smoking. F Appl Dev Psychol 1992;13:423-34.

214 Stanton WR, Silva PA, Oei TPS. Change in children's smoking from age 9 to age 15 years: the Dunedin study. Public Health 1991;105:425-33.

215 Sussman S. Two social influence perspectives of tobacco use development and prevention. Health Educ Res Theory Pract 1989;4:213-23.

216 Sussman S, Dent CW, Simon TR, et al. Identification of which high-risk youth smoke cigarettes regularly. Health Values 1993;17:42-53.

217 Torabi MR, Bailey WJ, Majd-Jabbari M. Cigarette smoking as a predictor of alcohol and other drug use by children and adolescents: evidence of the "gateway drug effect" of Sch Health 1993:63:302-6.

218 Tschann JM, Adler NE, Irwin CE Jr, et al. Initiation of substance abuse in early adolescence: the roles of pubertal timing and emotional distress. Health Psychol 1994; 13:326-33.

219 Urberg KA, Cheng C-H, Shyu S-J. Grade changes in peer influence on adolescent cigarette smoking: a comparison of two measures. Addict Behav 1991;16:21-8.

220 van Reek J, Knibbe R, van Iwaarden T. Policy relevance of a survey of smoking and drinking behaviour among Dutch school children. Health Policy 1991;18:261-8.

221 van Roosmalen EH, McDaniel SA. Peer group influence as a factor in smoking behavior of adolescents. Adolescence 1989:24:801-16.

222 van Roosmalen EH, McDaniel SA. Adolescent smoking intentions: gender differences in peer context. Adolescence 1992;27:87-105.

223 Waldron I, Lye D. Relationships of teenage smoking to educational aspirations and parents' education. F Substance Abuse 1990;2:201-15.

224 Wallace JM Jr, Bachman JG. Explaining racial/ethnic differences in adolescent drug use: the impact of background and lifestyle. Soc Problems 1991;38:333-57.

225 Wang MQ, Fitzhugh EC, Westerfield RC, et al. Family and peer influences on smoking behavior among American
adolescents: an age trend. F Adolesc Health 1995;16:200-3.

226 Weinrich S, Hardin S, Valois RF, et al. Psychological correlates of adolescent smoking in response to stress. $A m \mathcal{F}$ Health Behav 1996;20:52-60. 